Supplement of Biogeosciences Discuss., 11, 9471-9510, 2014

http://www.biogeosciences-discuss.net/11/9471/2014/

doi:10.5194/bgd-11-9471-2014-supplement

(C) Author(s) 2014. CC Attribution 3.0 License.

(c) (1)

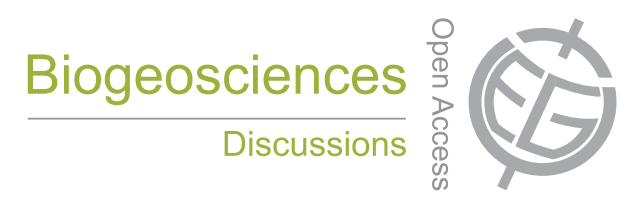

Supplement of

Forests, savannas and grasslands: bridging the knowledge gap between ecology and Dynamic Global Vegetation Models

M. Baudena et al.

Correspondence to: M. Baudena (m.baudena@uu.nl) 


\section{Figure A1}

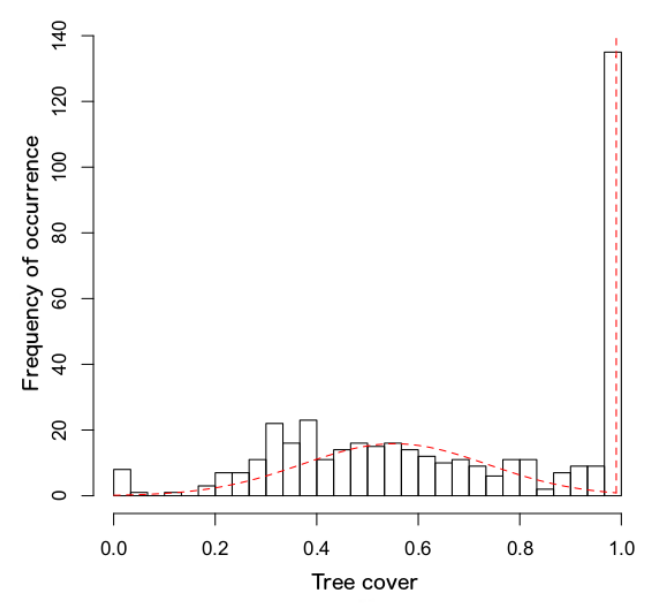

Fig. A1 Frequency distribution of tree cover for the aDGVM output, for mean annual precipitation between 800 and $1200 \mathrm{~mm} \mathrm{y}^{-1}$ mean annual rainfall. The distribution is bimodal (i.e. it is fitted significantly better by a superposition of two normal distributions, tested against the null hypothesis of unimodal normal distribution, $\mathrm{p} \ll<.001)$. 
Table B1 - The coefficient $b$ of the quantile nonlinear regression curves for the model and observational data. Values for the $90 \%$ and $99 \%$ quantile are reported.

\begin{tabular}{lccc}
\hline Data series & Figure panel & $\begin{array}{c}\boldsymbol{b , 9 0 \%} \text { quantile } \\
{\left[\mathbf{m m}^{\mathbf{2}} \mathbf{~}^{-\mathbf{2}}\right]}\end{array}$ & $\begin{array}{c}\boldsymbol{b , 9 9 \%} \text { quantile } \\
{\left[\mathbf{m m}^{\mathbf{2}} \mathbf{~ y}^{\mathbf{2}}\right]}\end{array}$ \\
\hline Field observation & Fig. 1A & $5.8 \mathrm{E}+05$ & $3.0 \mathrm{E}+05$ \\
MODIS observation & Fig. 1B & $4.1 \mathrm{E}+05$ & $1.9 \mathrm{E}+05$ \\
JSBACH/DYNVEG & Fig. 2A & $1.4 \mathrm{E}+05$ & $6.1 \mathrm{E}+04$ \\
LPJ-GUESS-SPITFIRE & Fig. 2B & $6.1 \mathrm{E}+04$ & $4.4 \mathrm{E}+03$ \\
aDGVM & Fig. 2C & $3.9 \mathrm{E}+04$ & $5.4 \mathrm{E}+03$ \\
\hline
\end{tabular}

